\title{
Article
}

\section{Feasibility of CO Fixation via Artificial Rock Weathering} Jeffrey C.-S. Wu, Jenn-Der Sheen, Shyan-Yeh Chen, and Ya-Chun Fan Ind. Eng. Chem. Res., 2001, 40 (18), 3902-3905 • DOI: 10.1021/ie010222I

Downloaded from http://pubs.acs.org on November 28, 2008

\section{More About This Article}

Additional resources and features associated with this article are available within the HTML version:

- $\quad$ Supporting Information

- $\quad$ Links to the 7 articles that cite this article, as of the time of this article download

- $\quad$ Access to high resolution figures

- $\quad$ Links to articles and content related to this article

- Copyright permission to reproduce figures and/or text from this article

\section{View the Full Text HTML}

\section{ACS Publications}




\title{
MATERIALS AND INTERFACES
}

\section{Feasibility of $\mathrm{CO}_{2}$ Fixation via Artificial Rock Weathering}

\author{
J effrey C.-S. Wu,* J enn-Der Sheen, Shyan-Yeh Chen, and Ya-Chun Fan \\ Department of Chemical Engineering, National Taiwan University, Taipei 10617, Taiwan
}

\begin{abstract}
Artificial rock weathering can potentially fix a large amount of $\mathrm{CO}_{2}$ generated from industrial and other sources with a slight expense of mechanical energy. From technological, economic, and environmental perspectives, artificial rock weathering is a preferential method to dispose carbon dioxide. Carbonate and hydrogen carbonate ions are formed spontaneously when carbon dioxide is dissolved in an aqueous solution owing to the negative Gibbs free energy. The calcium silicate component of wollastonite reacts with carbonate ions and becomes calcium carbonate and silicate. Such a reaction is economically feasible because this transformation does not require energy infusion. The products are naturally stable and can be discharged safely without pollution. Experimental results indicated that, in an aqueous solution, 1 ton of wollastonite could fix nearly $140 \mathrm{~kg}$ of carbon dioxide. No carbonation was observed when using talc under our experimental conditions. The study indicate that the reaction rate of artificial rock weathering may still be too slow for commercialization. Therefore, successful commercialization hinges on accelerating rock weathering reaction without increasing operational cost and increasing the efficiency of rock utilization.
\end{abstract}

\section{Introduction}

The human production of carbon dioxide has begun to change the climate; thereby, necessary steps must be taken to prevent further change. Many strategies have been proposed to remedy carbon di oxide, including chemical transformation and photocatalytic reduction of $\mathrm{CO}_{2}$ to valuable products, such as methanol or methane. ${ }^{1}$ The chemical fixation of carbon dioxide is one of effective and feasible means to reduce the concentration of $\mathrm{CO}_{2}$ generated from industrial and other sources in atmosphere. However, the Gibbs free energy of carbon dioxide is at low grade from a thermodynamics perspective. Any transformation of carbon dioxide requires energy infusion. Low-cost energy resources and carbon dioxide-free processes are essential to convert carbon dioxide to valuable products. Thus, upgrading carbon dioxide may not be economically practicable.

The downgrade of carbon dioxide via carbonation is another feasible route. The carbonation can be naturally carried through rock weathering. Rock weathering, a naturally spontaneous reaction, requires no energy infusion. The weathering process can be viewed as an acid-base reaction where an acid, $\mathrm{H}_{2} \mathrm{CO}_{3}$, is neutralized by a solid base such as rock. ${ }^{2}$ The rock weathering of wollastonite comprises of several reactions, and can be summarized in two reactions. Equation 1 is silicate weathering in which $2 \mathrm{~mol}$ of $\mathrm{CO}_{2}$ become hydrogen carbonate ion. Equation 2 is the formation of calcium carbonate in which $1 \mathrm{~mol}$ of $\mathrm{CO}_{2}$ is released. The overall reaction is that in which $1 \mathrm{~mol}$ of $\mathrm{CO}_{2}$ is fixed in calcium carbonate as shown in eq $3 .{ }^{3} \mathrm{~A}$ similar carbonation of talc may also occur as shown in eq $4 .^{4}$

* Corresponding author. E-mail: cswu@ccms.ntu.edu.tw. Telephone: +886-223631994. Fax: +886-23623040.
Silicate weathering

$$
2 \mathrm{CO}_{2}+\mathrm{H}_{2} \mathrm{O}+\mathrm{CaSiO}_{3} \rightarrow \mathrm{Ca}^{2+}+2 \mathrm{HCO}^{3-}+\mathrm{SiO}_{2}
$$

Carbonate formation

$$
2 \mathrm{HCO}^{3-}+\mathrm{Ca}^{2+} \rightarrow \mathrm{CaCO}_{3}+\mathrm{CO}_{2}+\mathrm{H}_{2} \mathrm{O}
$$

Overall reaction of wollastonite

$$
\mathrm{CO}_{2}+\mathrm{CaSiO}_{3} \rightarrow \mathrm{CaCO}_{3}+\mathrm{SiO}_{2}
$$

Overall reaction of talc

$$
\begin{aligned}
{ }_{1}^{1} \mathrm{Mg}_{3} \mathrm{Si}_{4} \mathrm{O}_{10}(\mathrm{OH})_{2}+ & \mathrm{CO}_{2} \rightarrow \\
& \mathrm{MgCO}_{3}+{ }^{4} / 3 \mathrm{SiO}_{2}+{ }_{1}^{1}{ }_{3} \mathrm{H}_{2} \mathrm{O}
\end{aligned}
$$

Geological estimates have indicated that the atmospheric concentration of carbon dioxide 100 million years ago was 20-30 times higher than the current level. At least half the amount of carbon dioxide was fixed by rock weathering, resulting in the current concentration of carbon dioxide, i.e., $300-400$ ppm, in the atmosphere. ${ }^{3}$ The total amount of carbon dioxide generated by human activity has doubled the concentration of carbon dioxide in the atmosphere since the industrial revolution. Currently, there is a net increase of 3 billion metric tons of carbon dioxide in the atmosphere annually. ${ }^{5}$ However, such an amount of carbon dioxide only engages a minute fraction of the geochemical carbon cycle because most of the carbon is stored in the form of calcium carbonate on earth. Even if all of the existing and reserved fossil fuels were to be burned, the amount of carbon dioxide released would only be 
Table 1. Compositions of Rocks

\begin{tabular}{lcc}
\hline & wollastonite (wt \%) & talc (wt \%) \\
\hline $\mathrm{SiO}_{2}$ & 50.48 & 55.98 \\
$\mathrm{Al}_{2} \mathrm{O}_{3}$ & 1.14 & 0.3 \\
$\mathrm{Fe}_{2} \mathrm{O}_{3}$ & 0.17 & 0.01 \\
$\mathrm{CaO}$ & 43.69 & 0.01 \\
$\mathrm{MgO}$ & 0.78 & 34.69 \\
$\mathrm{~K}_{2} \mathrm{O}$ & 0.14 & 0.03 \\
$\mathrm{Na}_{2} \mathrm{O}$ & 0.09 & 0.42 \\
$\mathrm{TiO}_{2}$ & 0.01 & \\
Ig. loss & 0.06 & 2.47
\end{tabular}

less than $0.007 \%$ of the total carbon mass on earth. ${ }^{3}$ Therefore, storing $\mathrm{CO}_{2}$ generated from industrial and other sources via rock weathering would only consume a very small amount of rock in the earth. Moreover, the disposal of products, calcium carbonate and silicate, would only negligibly impact the environment since they are natural materials.

I gneous rocks are essentially free of carbonate, thus making them ideal for $\mathrm{CO}_{2}$ fixation. While $\mathrm{Ca}$ - and $\mathrm{Mg}$ bearing minerals are available in abundant quantities, only certain rocks can most likely be processed economically. Wollastonite and talc, which naturally contain abundant $\mathrm{Ca}$ and $\mathrm{Mg}$, respectively, are promising candidates to investigate their ability to fix $\mathrm{CO}_{2}$ in an aqueous solution.

$\mathrm{CO}_{2}$ has been reduced to its current level over a span of millions of years. As expected, a major difficulty in artificial rock weathering is the reaction rate. Therefore, the task is to accelerate these natural reactions. Mild conditions, such as ambient temperature or pressure, are preferable because the deposition of $\mathrm{CO}_{2}$ is not for profit. Thus, expensive equipment or complex processes would be unacceptable in commercialization. This feasibility study presents a novel method using rock weathering to store carbon dioxide in an aqueous solution without adding reagents.

\section{Experimental Section}

Wollastonite and talc were obtained from the FengDeng Ceramic Co. (Taiwan). They are natural rocks (imported from China) pulverized to powder with very wide size distribution. The median sizes of wollastonite and talc are $\sim 440$ and $\sim 310 \mu \mathrm{m}$, respectively. These samples were used directly without pretreatment. Table 1 lists the compositions of wollastonite and talc as provided by the supplier.

The experiments were performed at room temperature and low pressure so that no special equipment was required. Carbon dioxide was fixed in an $0.5 \mathrm{~L}$ aqueous solution using a 2-L bottle as shown in Figure 1 . Wollastonite or talc was dispersed in distilled water in the bottle with a magnetic stirrer. The saturated $\mathrm{CaO}$ solution is near $0.13 \mathrm{~g} / 100 \mathrm{~mL}$ of water. The loading of wallostonite was intended to make a saturated $\mathrm{Ca}^{2+}$ solution, assuming the maximum dissolution of 43.69 wt \% $\mathrm{CaO}$ in wallostonite. Therefore, the excess loading of wall ostonite was $2 \mathrm{~g}$ in $0.5 \mathrm{~L}$ of distilled water, i.e., 4 $\mathrm{mg} / \mathrm{mL}$, and the same loading was applied to talc. The air in the bottle was purged by carbon dioxide several times, then $\mathrm{CO}_{2}$ pressure was increased to $202 \mathrm{kPa}$ by adjusting a back-pressure regulator. Next, the $\mathrm{CO}_{2}$ pressure variation was monitored by a pressure gauge. The absorption was performed from several hours to 22 days.

The solid content of solution after $\mathrm{CO}_{2}$ absorption was collected by centrifuging, then dried at $120{ }^{\circ} \mathrm{C}$ and

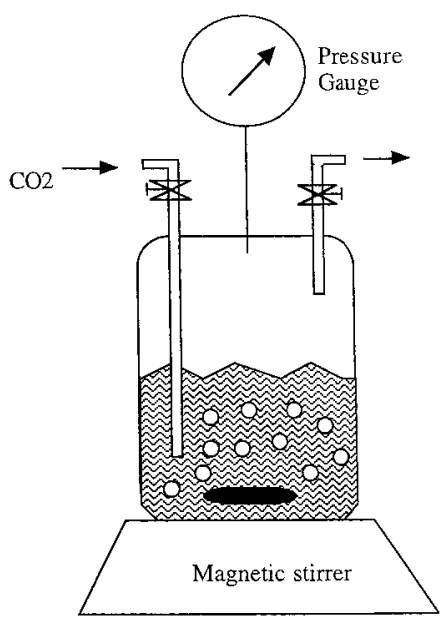

Figure 1. Schematic of $\mathrm{CO}_{2}$ absorption system.

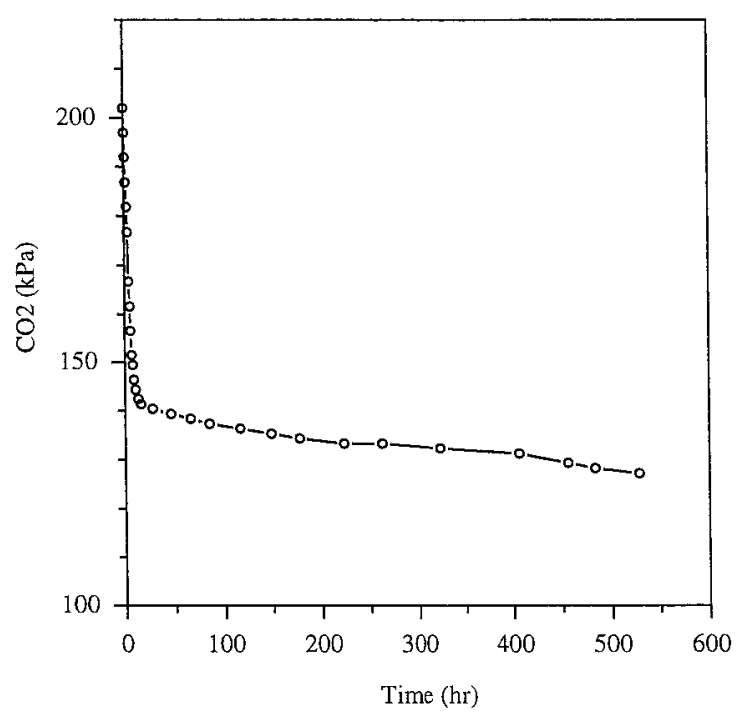

Figure 2. $\mathrm{CO}_{2}$ absorption by wollastonite in aqueous solution.

weighed. The amount of $\mathrm{CO}_{2}$ fixed in solid content was verified and measured by thermogravimetry (TGA) and differential thermal analysis (DTA).

\section{Results and Discussion}

Rock weathering occurs naturally on the earth as long as water, rocks, and carbon dioxide are available. ${ }^{2} \mathrm{An}$ obstacle to artificial rock weathering may be the dissolution of calcium silicate. ${ }^{6}$ Therefore, in this study, a powdered form of rock was used to accelerate the dissolution. The effective compositions of carbonation are $\mathrm{CaO}$ or $\mathrm{MgO}$. Therefore, the rock containing the most $\mathrm{CaO}$ or $\mathrm{MgO}$ is the best candidate. Table 1 lists two kinds of rocks used herein. Both rocks contain more than $50 \mathrm{wt} \%$ of $\mathrm{SiO}_{2}$. Wollastonite contains nearly 44 wt \% of $\mathrm{CaO}$ and talc contains nearly 35 wt $\% \mathrm{MgO}$. Notably, the composition was measured by elemental analysis and was not necessarily the free form of $\mathrm{CaO}$ or $\mathrm{MgO}$. These rocks are widely available and appropriate for investigating the $\mathrm{CO}_{2}$ fixation via carbonation.

Figure 2 indicates that the $\mathrm{CO}_{2}$ pressure decreases in a wollastonite aqueous solution in 22 days. The $\mathrm{CO}_{2}$ pressure initially declined rapidly in the first $5 \mathrm{~h}$ indicating the dissolution of $\mathrm{CO}_{2}$ and the formation of carbonate/hydrogen carbonate ions in an aqueous solution. The subsequent gradual decrease of $\mathrm{CO}_{2}$ pressure might be due to a minor leak of a valve or might be 


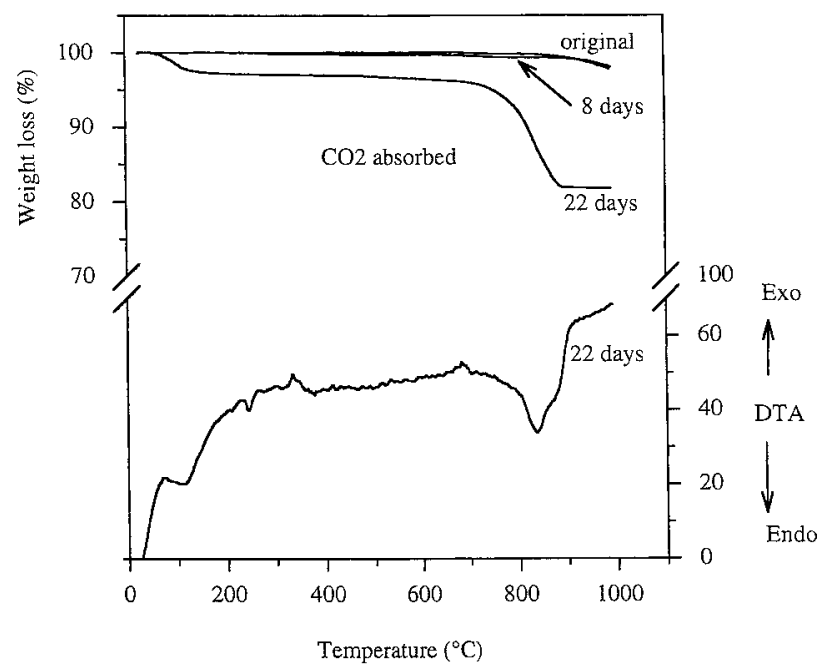

Figure 3. TGA and DTA of original and $\mathrm{CO}_{2}$ absorbed wollastonite.

attributed to the carbonation of calcium ion from wollastonite. This step involves the dissolution of wollastonite and is much slower than $\mathrm{CO}_{2}$ dissolution. The $\mathrm{CO}_{2}$ pressure only influences the concentration of carbonate/hydrogen carbonate ions in aqueous solution. Therefore, the variation of $\mathrm{CO}_{2}$ pressure is only a minor factor of the carbonation rate because the rate-limiting step is the dissolution of wollastonite.

Figure 3 depicts the TGA/DTA analysis of solid content after $\mathrm{CO}_{2}$ absorption using wollastonite. As shown in Figure 3 , original wollastonite and 8 days of $\mathrm{CO}_{2}$ absorption do not contain a volatile component up to $1000^{\circ} \mathrm{C}$. F or 22 days of $\mathrm{CO}_{2}$ absorption, a significant weight loss in the range $800-900{ }^{\circ} \mathrm{C}$ was due to the release of $\mathrm{CO}_{2}$. An endothermic reaction also supported the decomposition reaction of $\mathrm{CaCO}_{3}$. The reaction of wollastonite $+\mathrm{CO}_{2}=$ calcite $\left(\mathrm{CaCO}_{3}\right)+$ quartz $\left(\mathrm{SiO}_{2}\right)$ most likely occurs under a much milder condition. ${ }^{7,8}$ The weight loss is $\sim 14 \mathrm{wt} \%$ due to $\mathrm{CO}_{2}$ releasing. Theoretically, a nearly 25 wt \% loss due to $\mathrm{CO}_{2}$ is expected if 44 wt \% of $\mathrm{CaO}$ of wollastonite can be fully utilized. The carbonation rate could be so slow that it is not yet complete within 22 days. The dissolution of wollastonite and the carbonation in aqueous solution are thus the rate-determining steps. Another reason of slow rate may be a thin product layer, i.e., $\mathrm{CaCO}_{3}$, that developed on the outer surface of wollastonite particle retarding further carbonation.

Figure 4 displays the TGA/DTA analysis of solid content after $\mathrm{CO}_{2}$ absorption using tal c in 22 days. The TGA curves of original and $\mathrm{CO}_{2}$ absorbed talc are very similar. For $\mathrm{CO}_{2}$ absorbed talc, an additional small amount of weight loss was in the temperature range $100-200{ }^{\circ} \mathrm{C}$, suggesting the water release. The final weight loss above $700{ }^{\circ} \mathrm{C}$ could simply be the ignition loss of talc, which was also evidenced by an endothermic peak from DTA. Ther efore, the carbonation could be not detected in talc, at least under our experimental condition in an aqueous solution. Possibly, the $\mathrm{Mg}^{2+}$ cannot be rel eased from the talc in an aqueous solution under ambient condition; otherwise, the dissolution is too slow to be detected.

\section{Conclusion}

This study has demonstrated $\mathrm{CO}_{2}$ fixation by artificial rock weathering. Experimental results indicate that $\mathrm{CO}_{2}$

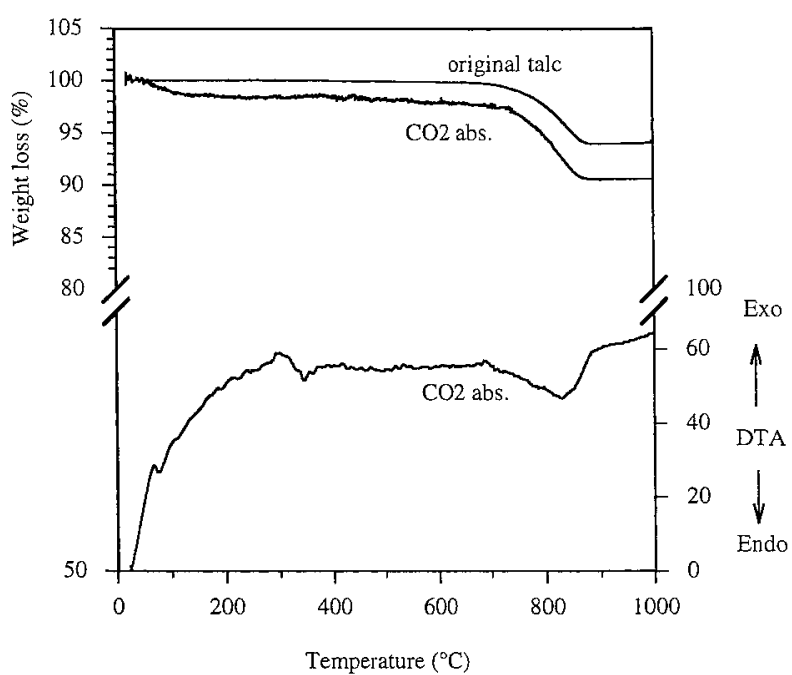

Figure 4. TGA and DTA of original and 22-day $\mathrm{CO}_{2}$ absorbed talc.

can be stored in rocks, such as wollastonite. According to the TGA results (Figure 3), $\sim 140 \mathrm{~kg}$ of $\mathrm{CO}_{2}$ can be stored by 1 ton of wollastonite. The pulverization of rock, such as wollastonite, requires electricity that may generate $\mathrm{CO}_{2}$ if fossil fuel is used. Kojima et al. estimated that $18.7 \mathrm{~kg}$ of $\mathrm{CO}_{2}$ would be released when 1 ton of wollastonite was crushed from $200 \mathrm{~mm}$ to 75 $\mu \mathrm{m} .{ }^{9}$ The fixation of $\mathrm{CO}_{2}$ via artificial rock weathering may still have a large net $\mathrm{CO}_{2}$ storage, even including other additional operations. Theoretically, nearly 345 $\mathrm{kg}$ of $\mathrm{CO}_{2}$ can be stored per ton of wollastonite if the entire $44 \mathrm{wt} \% \mathrm{CaO}$ is available for carbonation under most favorable conditions. Although the experiment results revealed that the amount of $\mathrm{CO}_{2}$ deposition was less than anticipation, the potential storage of $\mathrm{CO}_{2}$ still has a large capacity for improvement using wollastonite. Natural rock is abundantly available at a fairly reasonable price. The final products are environmentally friendly, since rock weathering has been producing them for several hundred million years.

The detailed mechanism of wollastonite carbonation may still be unclear. The kinetic rate is still too slow to keep up with the carbon dioxide produced by human activities. Although pure $\mathrm{CO}_{2}$ was used in this study, the rate of artificial rock weathering will not be substantially held back even if we use flue gas which contains only a few percent $\mathrm{CO}_{2}$. The major obstacle is the dissolution of wollastonite in water. The ion, $\mathrm{Ca}^{2+}$, must be released from the tetrahedral $\mathrm{SiCaO}_{3}$ structure to perform carbonation. Until now, the most direct method to accelerate dissolution is to provide large surface, i.e., small particles. Other chemical treatments, such as acid or basic reagents, might be effective but will be fairly expensive considering the enormous amount of $\mathrm{CO}_{2}$ storage. How to accel erate the reaction rate will be the key issue of commercialization.

\section{Acknowledgment}

The authors would like to thank the National Science Council, Tai wan, Republic of China, and Taiwan Power Corporation for financially supporting this research under Project Numbers NSC 89-2815-C-002-073-E and NSC 88-TPC-7-002-002. 


\section{Literature Cited}

(1) Xiaoding, X.; Moulijn, J . A. Mitigation of $\mathrm{CO}_{2}$ by Chemical Conversion: Plausible Chemical Reactions and Promising Products. Energy Fuels 1996, 10, 305.

(2) Nesbitt, H. W.; Young, G. M. Prediction of Some Weathering Trends of Plutonic and Volcanic Rocks Based on Thermodynamic and Kinetic Considerations. Geochim. Cosmochim. Acta 1984, 48 , 1523.

(3) Berner, R. A.; Lasaga, A. C. Modeling the Geochemical Carbon Cycle. Sci. Am. 1989, 260, 74.

(4) Lackner, K. S.; Wendt, C. H.; Butt, D. P.; J oyce, E. L., J r.; Sharp, D. H. Carbon Dioxide Disposal in Carbonate Minerals. Energy 1995, 20, 1153 .

(5) Houghton, R. A.; Woodwell, G. M. Global Climatic Change. Sci. Am. 1989, 260 (4), 36.
(6) Caruccio, F. T.; Caruccio, G. G. Method of Determining Weathering Characteristics of Rock Formations in Earth Moving Operations. US Patent 4,328,001, 1982.

(7) Heinrich, W.; Gottschalk, M. Metamorphic reaction between fluid inclusions and mineral hosts. I. Progress of the reaction calcite + quartz $=$ wollastonite $+\mathrm{CO}_{2}$ in natural wollastonite hosted fluid inclusions. Contrib. Mineral. Petrol. 1995, 122, 51.

(8) Ohnemuller, W.; Solf, A. Synthetic Wollastonite and A Process for Its Manufacture. US patent 3,967,974, 1976.

(9) Kojima, T.; Nagamine, A.; Ueno, N.; Uemiya, S. Absorption and Fixation of Carbon Dioxide by Rock Weathering, Energy Convers. Manage. 1997, 38 (Suppl.), S461.

Resubmitted for review March 7, 2001 Accepted May 8, 2001

IE010222L 